\title{
The Effects of Early Girl-Child Marriage in Mutasa District- Manicaland Province: A Cases Of Samanga 'A' Ward in Honde Valley
}

\author{
Mr. Offard Kanjanda \\ Ms. Getrude Vongai Chiparange \\ Lecturer, Zimbabwe Open University
}

doi: 10.19044/esj.2016.v12n11p539 URL:http://dx.doi.org/10.19044/esj.2016.v12n11p539

\section{Abstract}

Girl-child marriages in the developing countries of the world have caused a lot of suffering on the girl-children. According to Giddens (2009) issues of poverty, cultural practices, and political instability and gender inequalities have been noted as some of the major causes of girl-child marriages in developing countries. The situation has caused great concern to the communities of the global village because of the serious damages on the victims. Gage (2011) states that the status quo was exacerbated by the historical gender inequalities that continue to exist within families systems and place the girl-child an inferior citizen in her country. The girl-child remained vulnerable and segregated particularly, in educational advancement which is the key to self-empowerment, knowledge and skills development because of the high rate of girl-child marriage in the area. It appears there is little significant research on the matter in the developing countries. In order to establish some strategies to promote the girl-child's life-skills a study was conducted in Samanga 'A' in Honde Valley in Manicaland ProvinceZimbabwe. From a population of 1500 a sample size of 100 participants was selected using the cluster, systematic and purposive techniques because of their appropriateness to the two paradigms (Punch, 2009). Cluster technique was employed because the participants lived in different kraal-heads. The systematic technique was engaged because the participants were selected from every tenth household in each of the five kraal-heads. The purposive technique was used to select the influential participants such as local community leaders and the victims of early girl-child marriage. Marshall and Roseman (2006) support that purposive technique in qualitative study because the participants are powerful sources of information that is needed. Both qualitative and the quantitative paradigms were used in the study because some aspects of the study required simple response, while some of the questions demanded the participants' in-depth knowledge on the problem 
(Newman, 2010). A case study methodology was adopted because of its ability to focus on a specific issue in a concerned area (Croll, 2010). Data were collected through the use of direct observation, questionnaire with both open and closed ended questions and interviews. The data were descriptively analysed. The research revealed that the prevalence of early girl-child marriage was perpetuated by the society's cultural deprivation ideology which has since seen the girl-child discriminated in her efforts for self empowerment through education. The study recommended that there is need for the government to enforce and implement gender-sensitive policies which aim at protecting the girl-child in-order to enhance economic, social, cultural and political transformation for sustainable development in the community.

Keywords: Girl-child marriage, discriminate, self-empowerment, transformation, sustainable, gender-sensitive perpetuate and ideology

\section{Background to the Study}

According to the United Nations Children's Education Fund (UNICEF) (2005), globally 36\% of women aged between 20 and 24 were married or in union before they reached 18 years of age. United Nations Educational, Scientific and Cultural Organisation (UNESCO) (2004) also states that globally, 39 million girls aged 14-15 in developing countries do not reach secondary education due to several reasons that include early marriage. Sweetman (2006) also states that up to half of the girls in developing countries are mothers before they turn 18 years. Zimbabwe, as one of the developing countries is experiencing similar cases of early girlchild marriage.

There is much concern over the involvement of girls who are married before the national maturity age of 18 years since they still have dreams of acquiring educational achievements and finding employment to end the cycle of poverty in their families. The affected children experience a lot of problems ranging from social, psychological, educational, emotional and even physical. Many of them usually die before they reach the age of 45 years (Sweetman, 2006). Surveys carried out in some African countries offer alarming examples of early girl-child marriage. The table below shows the data about girls who are married before reaching 18 years in Africa. 
Table 1: Statistics of Girl Child marriages in Africa

\begin{tabular}{|c|c|}
\hline Country & Statistics of the country \\
\hline Ethiopia & $49 \%$ \\
\hline Mali & $65 \%$ \\
\hline Mozambique & $57 \%$ \\
\hline South Africa & $38 \%$ \\
\hline Togo & $39 \%$ \\
\hline Uganda & $54 \%$ \\
\hline Zimbabwe & $33 \%$ \\
\hline
\end{tabular}

Source: Demographic Health Survey (DHS) data from 1995 to 2010

According to Gage (2011) and Kanyi, (2008) the causes of early girlchild marriages in these countries are numerous and unsounded. These include poverty and cultural factors. The Central Intelligence Agency (2011) also argues that most of these countries are bordered by other countries that have history of wars and conflicts. Parents in such countries marry off their girls in order to protect them from rape and abductions from rebels.

According to the Zimbabwe Demographic and Health Survey (ZDHS) of 2010, the country's current economic and political situations have forced many families to violate children's rights, especially those of the girl-child. The table below shows the girl- child marriage prevalence in Zimbabwe:

Table 1.2 Statistics of girl child marriage in Zimbabwe by province

\begin{tabular}{|c|c|}
\hline Province & Prevalence of girl-child marriage \\
\hline Mashonaland Central & $50 \%$ \\
\hline Mashonaland East & $36 \%$ \\
\hline Mashonaland West & $42 \%$ \\
\hline Masvingo & $39 \%$ \\
\hline Matabeleland North & $27 \%$ \\
\hline Matabeleland South & $18 \%$ \\
\hline Bulawayo & $10 \%$ \\
\hline Harare & $19 \%$ \\
\hline Manicaland & $30 \%$ \\
\hline Midlands & $31 \%$ \\
\hline
\end{tabular}

Source: UNFPA report 2010

From the statistics above there is evidence that girl-child marriage is prevalent in Zimbabwe. According to ZDHS' (2010-11) research findings, revealed that about one in four teenagers aged between 13 and 19 have already begun child bearing because of poverty, religious belief systems and cultural practices. The BIAAG report (2012) also confirmed that ane school in Midlands, ten girls in Forms 2 and 3 left school due to early marriage while in Mashonaland East, 13 girls dropped out of school for the same reason in that year. From these few examples it is clear that there are many more cases of such nature which are just swept under the carpet in 
order to protect some few individuals to the expense of the innocent girlchild whose life is put to waste forever.

The Standard of 21 October, 2012 also reported on increasing cases of girl- child marriages in Mutasa District in Manicaland Province where nearly 50 girls drop out of school each year and get married to older men. This was revealed by the Education Officer, Mr. Derek Duma during the commemoration of the International Day of the Girl Child. Cultural beliefs were cited as one of the causes of the girl- child marriage in the area. Speaking at the same occasion, Headman Mandeya of Honde Valley said that some girls were married off to older men to appease avenging spirits. In Samanga 'A' Ward in Honde Valley, the issue of early girl-child marriage has reached an alarming level and the effects are just serious such that there is need to intervene in order to rescue the girl-child from further abuse as a result of early marriage. According to Mbiti (2008) child neglect has led to psychological, social, emotional, physical and educational problems. Current interventions lack commitment and coordinated action to eradicate this practice. Thus, this study sought to establish strategies that can help to eradicate the girl-child marriage in Mutasa District, with special emphasis to Samanga “A” Ward of Honde valley in Manicaland-Zimbabwe.

\section{Statement of the problem}

The status quo in Samanga Ward " $A$ " is very influential the early girl-child marriage due to their cultural and religious beliefs. This was intensified by the historical inequalities that exist between men and women about the position the position of girls in this community society. This practice has caused untold girl- child suffering which this study will reveal.

\section{Purpose of Study}

The purpose of the study was to analyse the causes and effects of early girl-child marriage so as to eliminate all forms social inequalities that deprive the girl-child of her right to a decent life in the society.

\section{Objectives of the Study}

The study was guided by the following objectives:

1. To identify factors leading to increased early girl-child marriages in Samanga “A” Ward of Honde Valley, in Manicaland.

2. To establish the effects of early girl-child marriage in Samanga A ward.

3. To suggest possible strategies to reduce early girl-child marriage in Samanga 'A' Ward. 


\section{Research Questions}

1. Why does early girl-child marriage exist in Samanga ' $A$ ' Ward in Honde Valley?

2. What are the (a) educational, (b) the social (c) psychological and (d) physical effects of early girl- child marriage on the girl-child?

3. What strategies can be employed to mitigate early girl-child marriage in Samanga A Ward?

\section{Theoretical Frameworks}

Although in qualitative approach the theory is grounded, it was important for the researchers to take a position on which theory or theories could guide the research. In this research the researchers used the systems and the grounded theories.

\section{Systems theory}

Barret (2010) believes that a system is a unified whole with interrelated parts. In this research, the researchers used the theory to find out how the girl-child lived with the new systems when they were married. This became the main purpose of this research in which the researchers would want to unveil the challenges faced by the girl-child as a result of early marriages. In the African culture, systems are important to promote collectivism and to maintain the value of "Ubuntu" within individuals (Saidel, 2010). It is within the context of this value that we would want to find out the extent to which this concept is inculcated in the community so that they are not divorced from their families and cultures.

\section{Grounded Theory}

It asserts that the researcher gets into a research without a concrete theory for the problem. As the researcher interacts with the participants and gets new knowledge, insights and concepts on the problem through continuous generation of new data, he/she establishes some theories from which to choose the most appropriate one(s) for the research (Punch, 2009). In this study the researchers used the grounded theory through immersion and debriefing with the participants as well as triangulation of instruments.

\section{Research methodology}

\section{Qualitative/case study method}

The qualitative paradigm was employed in this study because it enabled the researchers to collect in-depth information on what the community say or do in their natural settings, (Croll, 2010 Seidel, 2010).The design enabled the researchers to focus on the affective, cognitive and behaviour domains of the participants on the effects of early girl-child 
marriage. The question of perceptions and attitudes is an abstract concept and requires direct inquiry so as to unravel perceptions because they lie at the heart of the participants (Gage, 2011; Punch 2009). The researchers employed a qualitative/ case study because it was an appropriate method of studying of studying phenomena using a thorough analysis of an individual case among many. Marshall and Roseman (2006) contend that a case study provides a unitary character to the data being studied through triangulating facts that are derived from a variety of instruments. Therefore, the richness of a case study lies in its ability to provide in-depth understanding of important aspects of a new problematic area. Although this approach was successfully used the researchers experienced some difficulties because of multiplicity of perceptions resulting from the multiplicity of cultures in this area. To overcome this short coming, the researchers borrowed some quantitative techniques for data presentation and analysis.

\section{Population, Sample and Sampling Procedures}

During the time of study, the population of Samanga "A" Ward was 1500 families, statistical numbers provided by the Ward Councillor and kraal-heads. The sample constituted 100 participants (60 females and 40 males) for the research. The females were more than males because they were always available when the study was carried and most women had the responsibility of working in the banana and coffee plants to support the family. Because the researchers worked with different villages, stratified and systematic sampling techniques were used to make the sample. Using the systematic sampling technique, every $100^{\text {th }}$ house was selected. Purposive sampling was used to select six kraal-heads because of their positions and influence in the community.

\section{Research Instruments}

In order to collect data the researchers used the questionnaire, direct observation and interviews.

\section{Questionnaire}

The questionnaire had closed and open- ended questions to solicit indepth understanding of the phenomena (Meggitt, \& Grenier (2011). Questionnaires were easy to complete because they were self- administered and participants were given ample time of seven (5) days to complete the questionnaires. Among its many advantages, for the purpose of this study the questionnaire allowed the participants time space to express their views to the questions. 


\section{Direct Observation}

The researchers used direct observation to generate data in the participants' natural environment. This was rich because it enabled the researchers to record what was happening in the real world of the participants (Johnson, 2007). The researchers also observed the young women of different age groups struggling to do some manual work, daily activities and health outlook. This facilitated for accurate and unbiased data.

\section{Interviews}

For this particular study, the interview was the most prominent data generation tool that allowed the participants to describe the phenomenon under study (Punch, 2009). Interviews were regarded very reliable way of accessing people's perceptions, meanings, definitions of situations and their constructions of reality (Marshall \& Rossman, 2006). In order to understand others the researchers needed participants' constructions of reality to ask them -and ask participants in ways that they can provide in-depth description of the phenomenon.

\section{Data Collection Procedures}

In order to access entry into the field of study the researchers sought permission from the Headman, the kraal-heads, Ward Councillor and Ward chairperson. The councillor provided the researchers with statistical data for the population in the area. The data were collected using questionnaire, direct observation and semi-structured interviews.

\section{Data Presentation and Discussion}

Qualitative data were carefully coded and presented descriptively while quantitative data were presented in tables and supportive literature was added.

Item1: Which one of these definitions best fits early girl -child marriage?

\begin{tabular}{|l|l|l|l|l|l|l|}
\hline Variable & \multicolumn{3}{|l|}{ Number of Respondents } & Total & \% \\
\cline { 2 - 8 } & Male & $\mathbf{\%}$ & Female & $\mathbf{\%}$ & & \\
\hline $\begin{array}{l}\text { Early girl-child marriage is when a girl is } \\
\text { forced to marry at the age that is below 18 } \\
\text { years. }\end{array}$ & 35 & 35 & 35 & 35 & 70 & 70 \\
\hline $\begin{array}{l}\text { Early girl-child marriage is when a girl is } \\
\text { married without her consent. }\end{array}$ & 5 & 5 & 23 & 23 & 28 & 28 \\
\hline $\begin{array}{l}\text { Early girl-child marriage is when a young } \\
\text { single mother marries again }\end{array}$ & 0 & 0 & 2 & 2 & 2 & 2 \\
\hline TOTAL & $\mathbf{4 0}$ & $\mathbf{3 8}$ & $\mathbf{6 0}$ & $\mathbf{6 2}$ & $\mathbf{1 0 0}$ & $\mathbf{1 0 0}$ \\
\hline
\end{tabular}

Data generated from the participants through interviews and questionnaire to define early girl-child marriage, the research findings 
indicated that they had a common understanding of the definition. However, they came up with three major definitions as illustrated on the above table.

The responses above show that the community was aware of what early girl-child marriage was. Croll (2010) and Giddens (2009) shared the same sentiments that ...what society believes in is what it adopts as its culture, and this belief is passed on to the next generation. This suggests that early girl-child marriage is a culturally accepted socialization process in certain societies, despite it being a violation of human rights. However, whether with or without the consent of the child, girl-child marriage remains a serious violation of the child's rights because the young girl is immature to make decisions (Sweetman, 2006; \& Croll, 2010).

\section{Item 2: Is early girl-child marriage a human rights problem?}

Data generated from the participants to give perceptions on whether early girl-child marriage is a human rights problem reflected that the community in this area is aware that girl -child is a human being whose rights need to be observed and respected. With the Zimbabwe government making efforts to educate and empower its community on the rights of the girl-child, the research findings revealed that there still remain some gaps as evidenced by the attitude and practices by some members of the community who participated in this study. To confirm this finding one of the interviewed men stated that:

Headman 2

Hapana chikonzero chokusiya vakadzi
vachingo mbeyambeya vasinana
kuroorwa nokuti tinoda kuvedzera
uwandu hwevanhu munharaunda yedu.
There was no reason to leave females to
loiter around when they unmarried
because we want to increase the
population in our area and labour in the
families.

Among the interviewed participants one of them came up with a strategy to make people aware of the existence of the girl-child in the community. He stated that:

Councillor: There is great need for rescuing the innocent souls from further abuse so that they also enjoy their lives as the first class citizens in the planet. It is therefore important that Gender-based Movements step their awareness campaigns in order to give more education and information to the communities of Zimbabwe. 
From the citations above it reflects that lack of awareness and knowledge on human and children's rights within communities will cause more damage to the girl-child. This is congruent with the findings of the Universal Declaration of Human Rights (1948) which is calling for the abolition of bride price, elimination of child marriage and betrothal of young girls before the age of puberty.

\section{Item 3: Society's attitudes towards early girl-child marriage}

The research findings clearly indicated that in Samanga ' A' Ward people had mixed attitudes towards the early girl-child marriage. People have mixed attitudes on the early girl-child marriage. From the data generated from the participants the following comments depicted the community's attitudes towards early girl-child marriage: It is morally acceptable; We are comfortable with the practice; It is the girl's choice to get married; It is a bad practice on human beings; There is great need for positive change; No-one cares about it ; We sympathise with the girl-child.

The greater part of the responses condemned the early girl-child marriage as a shameful practice by some individuals who would want to justify protection of their own interests to the expense of the innocent girlchild. The implication here is that most communities do not condone such practice because it is a violation of human rights and is unjust.

Item 4: Educational effects of early girl-child marriage.

\begin{tabular}{|c|c|}
\hline THE EDUCATIONAL EFFECTS & FREQUENCY \\
\hline $\begin{array}{c}\text { Not allowed to attend school for fear of being proposed by other } \\
\text { males }\end{array}$ & $84 \%$ \\
\hline Poor academic performance. & $78 \%$ \\
\hline Not provided with adequate educational resources. & $79 \%$ \\
\hline Increase of illiteracy in the child. & $56 \%$ \\
\hline
\end{tabular}

Interviews carried with the parents and teachers on the educational effects of the early girl-child marriage showed that some children are not allowed to attend school because the parents fear that the daughters will be taken by some other males. Additionally, one of the teachers stated that:

Teacher 3

"In my class some girls perform very poorly at school and others are not provided with adequate educational resources such as text books and exercise books. This practice practice increases illiteracy levels in the child."

The citations above pointed out that the girl-child is neglected from receiving the desired academic achievement. There seems to be a strong belief that a certain gender (the girl-child) should not reach a certain 
academic level so that she remains a rich source for man's abuse. The cultural deprivation model assumes that this pattern of thinking is very dangerous because the community may find it difficult and irrelevant to accept change when, in fact, this is its culture (Haralambos and Holborn, 2011). This increases the girl-child's chances of remaining a second class individual and dependent in the society (Oxfam, 2004 \& UNICEF, 2000). From the Interpretivism point of view, some societies seem to have developed some neurotic behaviour simply because they were socialized in such culture(s). From the functionalism perspective, for a community to function effectively and productively for sustainable economic and social development, every member of the society should be an effective participant; and with resources as the social capital, shared equally among members (Giddens, 2009. Therefore, awareness campaigns against such behaviour should be scaled up so that the girl-child also benefits from educational resources so that she is able to determine her own future without disturbances and to live as a first class citizen in her own country.

\section{Item 5: The social effects of the girl-child marriage}

In order to show the social effects of the girl-child data generated from the participants depicted serious social effects on the girl-child as she gets married prematurely. There is evidence from direct observation that the girl-child's pattern of life in the marriage relationship was characterized by poverty, sorrow and anguish and therefore a slave in a marriage relationship.

\section{Item 6: The physical effects of girl-child-marriage}

Of all the twenty girls who were interviewed research findings showed that their responses were common. However, one of the girls who was physically abused stated that:

Girl-child 12

I was married at the age of 12 when I was doing Grade seven. My husband was older than my father. He asks me to fetch firewood from a far mountain with this pregnancy and I do all the house-hold chores for the whole family. 'Ndinorara ndaneta chaizvo,' I go to sleep tired. Similarly, one other girl sorrowfully stated that:

Girl 16:

I blame my father who pushed me into this mess. I am the fourth wife married to a Johanne Marange man who is almost 60 years and I am only 13 years. Most of the duties that are carried by a wife are very difficult for me 
to do. The family spends most of their time in the banana fields weeding and fetching firewood. This pains me because the work load is too heavy for my age.

From these citations there is a reflection that most of the girl-children are not enjoying their marriage relationships. From the data generated some of them confessed that they shall eventually go back home and continue with their educational studies.

The findings of this research were in agreement with Haralambos and Holborn (2011) who stated that the physical effects of girl child marriage negatively impact their lives since these marriages are not done to the best interest of the child. The CRC, Article 24 provides a basis for evaluating the laws and practices of States with respect to the protection of children. To pursue the best interest of children, parents and governments are responsible for protecting their children's health, education, development and overall well- being to the best of their capacities. Since early girl-child marriage disturbs the girl- child's health, particularly her sexual and reproductive health, which often results in maternal mortality and morbidity due to early pregnancies, the governments should take effective and appropriate measures to abolish such practice that prejudice the health of the girl- child.

\section{Conclusion}

The following conclusions were drawn from this current study:

- $\quad$ Early girl-child marriage is prevalent in societies whose cultural beliefs and attitudes are difficult to change. Early girl-child marriage is a culturally gender practice which discriminates equal opportunities and places the girl -child a second class citizen in her society. The research study revealed that early girl-child marriage as a cultural gender practice is prevalent in Samanga 'A' Ward.

- $\quad$ The prevalence of early girl-child marriage is greatly perpetuated by the society's mixed attitudes which have since seen the girl-child discriminated in her efforts for self- empowerment and self -emancipation through education. Education as a strong tool to acquire knowledge and life skills is regarded as the boy child's right to acquire.

- $\quad$ Dominance of patriarchal attitudes coupled with autocracy within some family systems make the girl child an inferior subsystem.

- $\quad$ Early girl-child marriage is a deliberate attempt by some individuals who intend to protect and achieve their own interest as evidenced in the Johane Marange sect.

- $\quad$ Some men take advantage of the girl child's poverty to cheat her into marriage by promising that she will be provided with everything. 
- $\quad$ Early girl-child marriage is a violation of children's rights because the child is deprived of her personal freedom, effective social interaction and personal achievement for sustainable social, economic, spiritual and psychological development

- $\quad$ he effects of early girl-child marriage are generally a result of poor family backgrounds. When parents fail to educate the girl child no one else will educate her and it means her future life is doomed

\section{Recommendations}

The research recommended that:

- $\quad$ There is great need to make it mandatory that every girl-child must attend and attain secondary education which will make her concentrate on school work, socialise on the effects of early marriage and gains life skills for economic growth and sustainable development.

- $\quad$ Gender inequality should be a teaching and examinable subject from primary to secondary education so that the society is educated for continued sustainable economic, moral, social, political and spiritual transformation and development.

- $\quad$ More community awareness and empowerment programs should be intensified in order to reach all corners of the country and follow up by the government should be done to check and evaluate on the effective implementation of the programs. This effort will change undesirable behaviours and attitudes on the girl-child.

- Communities, traditional leaders and religious groups should be capacitated with knowledge and skills that enable them to enforce mechanisms that eliminate the practice of girl-child marriage.

- $\quad$ Recovery and social reintegration services should be available for all girl child victims of girl child marriage to enable them to regain their damaged ego for continued sustenance of life.

- $\quad$ Reporting mechanisms available to children and their representatives must be safely accessible to enable the reporting of girl child marriages, taking into account the special difficulties for the child and their advocates caused by the dominant approval of the practice. Reporting must lead to appropriate action to protect children in their best interest.

\section{References:}

Barret, L. (2010) Poverty and Famines: An Essay on Entitlement and Deprivation. Oxford: Claredon Press.

Borg, W.R. \& Gall, M.D. (2009) Educational Research and Introduction: New York: Longman. 
Borgdan, R.C. and Biklen, S.K. (2002) Educational Research: Longman, New York

Bunting, A. (2012) Particularity of Rights, Diversity of Contexts: Women, International.

Casey, D.(2008).An introduction to Research methods. Pretoria.

Clark S., Bruce J. and Dude A. (2004) "Protecting young women from HIV/AIDS: The case against child and adolescent" in International Family Planning perspectives, vol.32.No 2.

Croll, B. (2010) Emerging Strategies in the Prevention of Domestic Violence', The Future of Children - Domestic Violence and Children, vol. 9, no. 3

Customary Marriages Act Chapter 5:07 consolidated as of 2004

De la Roha, K.G. (2009) The Temptations in the Family Cycle in Developing World, New York, McGraw Hill.

De Smedt, J. (1998), “Child Marriage in Rwanda Refugee Camps”. Africa; Journal of the

Department of Economic and Social Affairs, Division for the Advancement of Women (2011)

Diana Brown, D. (2006), International Humanist and Ethical Union, IHEU.

Gage, H. (2011) Understanding the concept of Child Rearing in SubSaharan Africa, New York, McGraw Hill.

Giddens, A. (2009) Sociology, New York, CA: Sage.

Haralambos, M and Holborn, M. (2011) Sociology: Themes and Perspectives, Britain. Collins Publishers

Hill, M.(2005) Basics of Qualitative research. Newbury Park, CA: Sage.

Hudson, D. \& Ozanne, G. (2008) ). Purposeful Program Theory: Effective Use of Theories of Change and Logic Models. San Francisco, CA: Jossey Bass

Johnson, H, (2007) The relationship between childhood sexual abuse and sexual health practices of homeless adolescents. Adolescence, 41 (162), 221234.

Kanyi, B (2008) For Better or for worse: Nigeria, Longman.

Locoh T. (2008). Early marriage and motherhood in sub-Saharan Africa, African Environment

Woman and African: Cutting Both Ways' Editions, p. 3

Marshall, C. and Rosseman G.B. (2006), Designing Qualitative Research: Sage Publication, London.

Mbiti, J.S. (2008), African Religions and philosophy. London: Heinemann.

Meggitt, C., \& Grenier, J. (2011).Child Care and Education. London

Ministry of Education and Sports (2001). Country Report: Uganda. Entebbe:

Government Printer and Publishers. Religious Research, 35, 117-133. 
Momsen, D. (2009) Effects of Domestic Violence on Children and Adolescents: An Overview', The American Academy of Experts in Traumatic Stress. Washington DC: Sage

Naila, H. (2008) The research methods in social sciences. London: Martins Prep.

Newman, S.T. (2010) The Social Work Student's Research Handbook. New York: Haworth Social Work Practice Press.

Plan RESA (2012) BIAAG Report: Girls access retention and completion of primary and secondary school. BIAAG

Population Council (2008) Child marriage in Francophone West Africa; NY; USA.

Punch, K.F. (2009). Research Methods in Education: Sage Publication, London

Rev Mujinga MwambaKura (2011), The Growth of one initiated Church in Zimbabwe, Johanne Marange’s African Apostolic Church.

Seidel, J.V. (2010).Qualitative data analysis. Retrieved from www.qualisresearch.com

Seidel, R. (2010) Interpreting the Family Life in Africa, Boston: Merrill.

Sweetman, C (2006) Education, Democracy and Poverty Reduction in Africa, Comparative Education, Washington DC: Sage

UN (2007) The millennium Development Goals, Report 2007. New York. Retrieved November 12, 2012

UNFPA, (2005) Child marriage face sheet

UNICEF (2000) Early marriage: Whose right to choose? Mission Statement of the Forum on Marriage and the Rights of Women and Girls.UK: Author.

UNICEF (2001a) Call for Stopping Child Marriages. Retrieved 2 March 2013

http://www.afrol.com/categories/women/wom025childmarriages.html from UNICEF (2005), Early marriage: A harmful traditional practice. UNICEF: New York

Zimbabwe National Statistics Agency (ZIMSTATS), Zimbabwe Multiple Indicator Monitoring Survey (MIMS) 2009 report. August 2010 pg 117 